\title{
Achieving Superior Organizational Performance via Big Data Predictive Analytics: A Dynamic Capability View
}

\author{
Shivam Gupta \\ Montpellier Business School, \\ Montpellier Research in Management \\ 2300 Avenue des Moulins, Montpellier - 34185, Occitanie, France \\ Email:sh.gupta@montpellier-bs.com \\ Vinayak A. Drave \\ Indian Institute of Technology Kanpur \\ Department of Industrial and Management Engineering \\ Kalyanpur, Kanpur - 208016, Uttar Pradesh, India \\ Email: vinayak@iitk.ac.in
}

\author{
Yogesh K. Dwivedi* \\ Emerging Markets Research Centre (EMaRC), School of Management \\ Swansea University Bay Campus, Fabian Way, Swansea SA1 8EN, UK \\ Email: y.k.dwivedi@swansea.ac.uk \\ (*Corresponding Author)
}

\begin{abstract}
Abdullah M. Baabdullah
Department of Management Information Systems

Faculty of Economics and Administration

King Abdulaziz University, Jeddah, Kingdom of Saudi Arabia

Email: baabdullah@kau.edu.sa
\end{abstract}

\section{Elvira Ismagilova}

School of Management, University of Bradford, UK

Email: e.ismagilova@bradford.ac.uk

\begin{abstract}
The art of unwinding voluminous data requires expertise to extract meaningful decisions from the acquired information. To face today's challenges, users are going to great lengths to free themselves from constraints and work edge-to-edge to achieve higher market, financial and operational performance. It is clear that organizations seek to exploit the resource that they have invested into the greatest possible extent, but often fail to reap their true potential. The development of resource-based capabilities stands out as the aspect most affected by this for firms in recent times, though it has also been studied by previous scholars. It is challenging to find evidence that highlights the effect of strategic resources in the development of dynamic organizational capability in the wealth of available literature.
\end{abstract}


This study is a two-fold attempt to examine both the relationship between organizational capabilities, i.e. big data predictive analytics, and the achievement of superior organizational performance along with the effect of control variables on superior organizational of performance. We tested our research hypotheses using cross-sectional data from 209 responses collected using a pre-tested single-informant questionnaire. The results underpin the criticality of human factors when developing dynamic analytical capabilities to achieve superior performance.

Keywords: Big Data Predictive Analysis (BDPA); Market Performance; Operational Performance; Financial Performance; Dynamic Capability View Theory

\section{Introduction}

Unlike in the past, when only a handful of organizations enjoyed the use of state-of-the-art technology, now almost all organizations have access to it, though they lack the proper skills to leverage it (Dubey et al., 2019a). Companies focus on improving their operational and financial performance with extensive strategies that aim to take advantage of information (data) that is available as big data (Dwivedi et al., 2017; 2019; Duan et al., 2019; Srinivasan \& Swink, 2018). Gupta \& George (2016) asserted based on Gartner's study (Gartner, 2013) of 720 firms that $64 \%$ of organizations invested a fixed amount in acquiring big data. Companies often mistakenly make substantial investments to acquire data before investing in technology and without acquiring and retaining the right human capital. A recent study (Dubey et al., 2019a) has presented evidence pointing out many inefficient practices that create a barrier to sustainable growth. Often organizations do not place enough importance on human interpretative skills and rely primarily on machine output. This stands out as one of the significant factors for failure when deploying BDPA. Big data provides both vertical and horizontal vertices of information that need to be complemented with the capabilities of proper technical skills for processing and managerial skills for taking rational decisions. Dubey et al. (2019a) and Gunasekaran et al. (2017) outlined a plethora of possibilities (healthcare supply chain, transportation, etc.) for leveraging big data predictive analysis and achieving sustainable organizational growth. Firms aspire to anchor their resources and operations with information and communication technologies (ICT) until they become a core capability in the organization (Kache \& Seuring, 2017; Schoenherr \& Speier-Pero, 2015; Waller \& Fawcett, 2013). Gupta \& George (2016) classified BDPA capabilities into tangible, 
intangible and human skills that can lead to higher organizational performance (market performance and operational performance). Building organizational capability requires the bundling of strategic resources that rely on a few distinctive skills (Brandon-Jones et al., 2014). BDPA needs to be developed to a much greater extent; it is still in the embryonic stage in most industries. However, many companies blindly race towards the most in vogue technologies without assessing their actual utility, putting an unnecessary financial burden on both companies and their vendors. Organizations whose primary focus is on sustainable businesses operations (Teece et al., 1997) should consider a dynamic capability view (Hitt et al., 2016) so that these organizations become capable of developing not only distinct but adaptable capabilities. These dynamic resource capabilities assist organizations in leveraging these capabilities by providing their operations with adaptability and becoming able to adopt, built and reconfigure their internal and external processes. BDPA can provide competitive advantages (Akter et al., 2016) in highly dynamic market conditions with proper guidance if nurtured over time. Gupta \& George (2016) showed the positive relationship between BDPA capabilities and organizational efficiency and rational decision making. A strong assertion by Hitt et al. (2001) states that merely adopting technology will make no difference if it is not supported by the right human skill sets to transform BDPA from a resource to a capability (Akter et al., 2016; Gupta \& George, 2016; Wamba et al., 2017). Dubey et al. (2019a) highlight the importance of human skills when developing BDPA capabilities. Often researchers interchangeably use the terminologies of market performance and organizational performance, providing evidence of a win-win situation for organizations and the market, but market-oriented firms ironically have the least amount of per unit profit, leading to a unit price that is much lower than that of their competitors. Acting as a facilitator, firm size can complement business operations when scaling up technologies via economies of scale. Every organization runs with a set of objectives and an orientation with different drivers and components. It is sometimes difficult to compare two firms, even when they operate in the same industry. Both firm size and industry type work as enablers and at the same time act as disablers, which might affect organizational performance in all three vertices, i.e. operational, financial and market. In the wealth of literature, many scholars have clearly explained the importance of a firm's big data analytical capability and organizational performance in the broader sense. There is a narrow understanding of the importance of human skills (managerial and technical skills) when developing dynamic capabilities like BDPA and the impact of these capabilities on achieving higher grades of overall performance in the firm. There is a dearth of empirical support that demonstrates the direct relationship between firm 
size, industry type and a firm's overall performance. This study is a bi-fold attempt to address the objectives for examining the direct relationship between organizational capability and superior organizational performance in the sense of dynamic capabilities, and to test whether industry type and industry size have any impact on the dependent variables above.

This paper is laid out in six sections. The next section (Section 2) discusses the theoretical background for the research in order to understand the fundamental concept and related literature. It provides reference literature for big data predictive analytics capabilities (managerial skills, technical skills) and superior organizational performance (operational, financial and market performance). In Section 3, we develop the research framework that shows the interconnection between BDPA capabilities and overall organizational performance. Based on this research framework, the study proposes six research propositions. In Section 4, we discuss the research methodology that was followed, i.e. the survey, analysis of the collected data and the results of the empirical research that serve as the basis of our conceptual model (Figure 1) and the impact of BDPA capabilities, firm size and industry type on superior organizational performance. Section 5 discusses the theoretical contribution and managerial implications of this research. Section 6 opens up possibilities for future research bearing in mind the limitations of the current research. Our paper finally reaches a conclusion after establishing a positive relationship between BDPA capabilities and overall organizational performance. We also discuss the effect of control variables such as firm type and size (in terms of operations and human strength) on superior organizational performance. To further strengthen the study, the operationalization of constructs is given in Appendix A, combined loadings and cross-loadings are shown in Appendix B and indicator weights are presented in Appendix C.

\section{Theoretical Background}

\subsection{Big Data Predictive Analysis (BDPA)}

Information stands out as the most potent fuel from which an organization can derive success. Data can be understood as information in a specified format following a set of closed patterns and used according to requirements. Data can be sorted, classified, arranged and analyzed using proper tools and technology. George et al. (2014) have given five major sources of data, namely, "public data, private data, data exhaust, community data and self-quantification data". Data is the next most crucial factor after labor and land. According to Gupta \& George 
(2016) data is the prerequisite for taking decisions, as data-driven decisions are considered inherently more rational and wise. Exponential growth in data leads to the generation of voluminous and complicated information, but if analyzed skillfully, it can be used as a weapon to acquire a competitive advantage leading to sustainable growth (Galbraith, 1973). The basic understanding of BDPA is that it provides a technique to process data that is inherently voluminous and that possesses high "velocity and variety" (Duan \& Xiong, 2015; Wang et al., 2016; Zhou et al., 2014). To clarify, big data predictive analysis is nothing but the technique of unwinding voluminous data in a format that will assist in the taking of critical decisions for business operations. The complex nature of big data makes it hard to handle and decode. The human skills of a specific organization are necessary for handling the criticality associated with predictive analytics i.e. "data capture, storage, transfer \& sharing (system architecture), search, analysis and visualization (data analytics)" (Chen et al., 2012; Duan \& Xiong, 2015; Erevelles et al., 2016). According to Azeroual et al. (2018), data profiling could be used as a tool to maintain high standards of data.

High-tech organizations whose operations are highly dependent on technology can distinguish themselves by mastering the process of data analytics. Examples like Big Open Linked Data (BOLD) (Dwivedi et al. 2017) can bring functional innovation to organizations. According to Wamba et al. (2017), BDPA can work on a high level of organizational capability by bringing together all the strategic resources. Akter et al. (2016) studied direct outcome of resources and BDPA on superior organizational performance.

\subsection{Dynamic Capability View}

The past decade has witnessed the emergence of DCV as one of the most influential views in management (Schilke, 2014). Although it is an extension of the resource-based view, which explains that organizations can obtain advantages over competitors based on their resources and capabilities, DCV explains the ability of a firm to sustain competitive advantages in dynamic environments (Priem \& Butler, 2001). Conceived from "Schumpeterian's gale of creative destruction", dynamic capabilities work to enable organizations to integrate, create and reconfigure their resources in constantly changing marketplace settings (Teece et al., 1997). Regardless of variations in definitions, there is a consensus in the literature that dynamic capabilities are a bundle of "identifiable and specific routines" (Eisenhardt \& Martin, 2000). Past studies have examined the use of information technology in developing 
organizational capabilities that could help organizations to further improve their current mode of operations (Mikalef \& Pateli, 2017; Mikalef et al., 2016; Pavlou \& El Sawy, 2006; Wang et al., 2012).

\subsection{Developing BDPA into Dynamic Capabilities}

Capabilities are mostly defined as a collection of strong, repetitive abilities that are found in part in tacit knowledge (Winter, 2003). Though easy to adopt, BDPA is difficult to develop into a capability, as it requires competitive skills to supplement it. Teece et al. (1997) argued that firms cannot simply acquire it; they have to build it. It is the process of converting raw resources into high-end capabilities (Sirmon et al., 2011). Past research (Hitt et al., 2001) showed that the adoption of technology alone will not make any difference unless until it is supplemented with the right human skill sets to transform BDPA from resource into capability (Akter et al., 2016; Gupta \& George, 2016; Wamba et al., 2017). Furthermore, these capabilities can be transformed into dynamic capabilities by introducing new processes into the system and nurturing the culture of knowledge in the organization. In order to achieve dynamic capabilities, the overall organizational performance requires a steady upgrading of technology along with people who can leverage that particular technology. This brings us to the role of the human quotient, which not only helps to establish technology, but also plays a vital role in achieving the maximum potential of that technology, and at a certain level it even overperforms as a competitive advantage for the organization. Taking this uniqueness into account, an absence of competitive human factors (technical and managerial skills) will negatively affect the organization when leveraging the true value of resources (technology and organizational knowledge), but the presence of these skills not only helps the organization to build a culture of knowledge, but also helps when utilizing the resources (technology) to an extent that cannot be compared to others, making it a non-imitable capability for an organization. It is therefore evident that developing capabilities is highly depending on the resources that an organization plans to acquire (de Camargo Fiorini et al., 2018).

2.3.1. Managerial Skills: Human capital is one of the core resources that can be acquired through proper talent hunting. However, its growth and sustainability depend on the knowledge culture in an organization. The literature defines it as a unique resource that can be acquired but not imitated. Companies invest in human capital expecting to leverage their skill sets and intellect and to develop it as a competency. Regardless of the organizational 
hierarchy, companies introduce and incubate next-level technological knowledge to elevate the learning environment. According to Gupta \& George (2016), managerial skills develop over time and can be nurtured by providing a learning environment inside the organization. Organizations in which personnel are competitive in taking managerial decisions will find more significant methods of growth and demonstrate outstanding performance in both standard and dynamic conditions. Technology is of no use if the manager is not able to extract insight and take strategic decisions by using his/her intellectual skills. Soft skills such as interpersonal skills and acquiring trust are non-imitable and also non-substitutable (Mata et al., 1995). According to Galbraith (1973), companies should seek to obtain personal skill sets, which could be utilized for information processing at the time of technology failure or technology deficiency.

2.3.2. Technical Skills: Technical skills are often categorized as the expertise/overall understanding of specific technology along with familiarity with its functions and outputs when forming a set of data. Firms harm themselves by not acquiring technical skills. This leads to poor coordination of operations and continuously hampers the economic performance of the organization (Gupta et al., 2016). Some of these skills include mastery of machine learning, artificial intelligence, statistical analytics, data extraction and cleaning, and last but not the least the understanding of programming languages (Davenport, 2014; Russom, 2011). Another factor contributing to the failure of IT systems in organizations is that organizations often become biased while choosing investment options and end up investing considerable resources in technological infrastructure and giving less importance to acquiring technical skills (Dwivedi et al., 2015). Organizations' technical skill sets should be able to adjust to the advancement of technology. Lean practices lead to the outsourcing of technical skills according to requirements, thus creating a considerable crisis of technical capabilities in an organization. According to Gupta \& George (2016), it is not only the technology, but also the skill that ensures the desired outcome of the business. Analytical skills are not limited to responsibilities or job roles; organizations should provide sufficient opportunities for human resources to develop analytical thinking among all employees throughout the organization (Prescott, 2014). This should be in addition to the technology and updated to adjust to technological advancement; only then can it produce a stable output and provide a competitive advantage that can be leveraged for long-term operations (Dubey et al., 2019a). 


\subsection{Organizational Performance}

Organizations try to build sustainable performance via proper blending of organizational capabilities and resources to maintain the equilibrium between operational and economic performance; this involves sustaining and expanding economic growth (Székely \& Knirsch, 2005). Gupta \& George (2016) show the positive relationship between big data analytics and superior organizational performance. This relationship impacts performance in both negative and positive ways. The combination of quality management practices such as just-in-time, lean manufacturing and higher accuracy in data predication will help serve the market, ensuring continuous growth and sustainable market performance. The long-term sustainability of an organization depends on three vertices of performance, i.e. market, financial and operational performance. The linear relationship between organizational capabilities and dimensions of organizational performance should urge business owners to develop dynamic capabilities after utilizing strategic resources.

\subsubsection{Financial Performance}

The highest priority for organizations while achieving superior organizational performance is to have higher growth performance with regard to their financials, which can be achieved by inter-organizational information systems leading to increased supply chain capabilities (Rajaguru \& Matanda, 2013). A higher degree of green practices produces excellent results in economic performance (Zhu \& Sarkis, 2004). Firms reduce by-products and emissions from the production process while leveraging lean systems to improve the process, which results in better economic performance (Pil \& Rothenberg, 2003). Previous research has tested improved methods and efforts and proven their positive effect on a firm's economic performance (King \& Lenox, 2001). One of the primary goals of any organization is to capture a large share of the market, which is only possible when organizations manage to have respectable margins and profits not only through their sales but also from monetary savings, because their optimized operations strengthen the company's financial aspirations. By maintaining economic gains, organizations can also strategically develop capabilities that can complement superior organizational performance and help capture market share. Economic performance helps to build an ecosystem for business process operations and makes it possible to meet shareholders' demands.

\subsubsection{Market Performance}


Businesses tend to focus on their market performance and operational efficiencies to increase profitability. Gupta et al. (2014) emphasize that market performance can be achieved through innovation, which has a parleying effect between market orientations and organizational learning. Obtaining superior and sustainable market performance depends on the alliance between quality management practices like just-in-time and lean manufacturing, which facilitate a strong brand image. Capable big data predictive analysis techniques equip organizations to efficiently manage the inflow of data so that it can accurately predict market requirements. This means that organizations can align their business processes and business strategies to cater to the current market needs at their highest potential and help gain a better understanding of market aspirations to deal with future demands.

\subsubsection{Operational Performance}

When the actual value of performance exceeds expectations, then the setup of the firm is in a state of operational efficiency. Developing a substantial predictive capability helps the organization reap the greatest possible advantage through big data analytics, which elevates the supply chain performance by shedding light on the structure (Barratt \& Oke, 2007) and leading to higher organizational performance (Gunasekaran et al., 2017; Schoenherr \& Speier-Pero, 2015; Waller \& Fawcett, 2013). Big data complements information technology along with the utilization capability, which helps enhance organizational performance (Kung et al., 2015). This high degree of operational performance results in cost-effective operations that can make it through difficult times and support overall sustainability. BDPA action capability can form the basis for this operational elevation. It also can enable organizations to make appropriate decisions (Keeso, 2015; Roman Pais Seles et al., 2018).

\subsection{Firm Size}

Large organizations inherently have better options to mitigate risks and make their operations more scalable. They can also easily weather drastic changes in technology compared to smaller firms. On the other hand, they are less agile in their operations and suffer more frequently from underutilization of acquired resources. Organizations that are racing towards achieving excellence in their operations and gaining a larger market share and high profits are continuously expanding not only horizontally but vertically. Under certain market conditions, it is also true that smaller firms can surpass the profit levels of larger companies (Lotti \& Santarelli, 2004). On the whole, it is debatable whether the size of the firm actually affects organizational performance while impacting its scale of operations. 


\subsection{Industry Type}

In many organizations, firms are classified into different categories of industry based on the nature of their work and capabilities regardless of size. Even a small company can make considerable profits. Past academics (Fatorachian \& Kazemi, 2018) have discussed enablers of the fourth industrial revolution, which allow industries to become technologically advanced in order to facilitate swift flows of information as well as business orientation. Industries may sometimes be subject to constraints while deploying or upgrading technological advancements due to their internal structure. It is often seen that industries with short product life cycles have more advantages over other industries, as they are calibrated for continuous structural and fundamental changes to accommodate new product development.

\section{Theoretical Model and Hypothesis Development}

This research follows the Dynamic Capability View (DCV) discussed earlier in previous studies (Barney 1991) as an extension of the resource-based view (RBV). The dynamic capability view explains a firm's distinct and sustainable advantage over the other players in most competitive environments. DCV can be better understood as a firm's ability to respond to continually changing environments by developing internal and external competencies (Teece et al., 1997). This study is rooted in the DCV concept and asserts that organizations should nurture capabilities that can be non-imitable and not only provide competitive advantages but also make the organization agile enough to leverage technological opportunities. Henderson \& Venkatraman (1993) argued that DCV is an on-going process of change rather than a temporary event. Akter et al. (2016) argued that BDPA may be a dynamic capability through which firms can achieve a higher level of organizational sustainability and edge out others, provided the operations are transparent and adaptive. Despite having vast strategic resources, some organizations fail or are unable to reach their desired outcome. The viewpoint provided by DCV therefore enables firms to crucially understand how capability can improve organizational sustainability in turmoil conditions.

Out of the three strategic resources of tangible, non-tangible and human skills (technical and managerial skills), human skills stand out as the most crucial to executing and developing BDPA as a capability (Barney, 1991; Gupta \& George, 2016) and directly contributing to market operational performance. Bilateral information flows in the system require a higher degree of transparency and trust, which can be achieved through big data 
predictive analysis. Past research has shown that big data analytics bring more transparency and flexibility into operations, leading to better performance (Gupta \& George, 2016).

Despite increasing interest in BDPA, only a small amount of literature is available (Akter et al., 2016; Dubey et al., 2019a; Gupta \& George, 2016; Hitt et al., 2016; Teece et al., 1997; Wamba et al., 2017). Garmaki et al., (2016) argued that big data is not only about data and tools, but incorporates a wider array of components. Firms must face a series of challenges before successfully executing BDPA (Mikalef \& Pateli, 2017; Vidgen et al., 2017). Nevertheless, it is still difficult to consider BDPA as a skill (Cao \& Duan, 2014; Grover et al., 2018; Kung et al., 2015) or a capability (Olszak, 2014; Papadopoulos et al., 2017). Traditionally, it is a culmination of targeted IT resources that are intended to provide decision support information. Firms periodically combine their resources (technical skills and managerial skills) with the hope of forming a distinct capability that helps organizations to project themselves as data-driven decision makers and optimal operational capacity firms.

Though BDPA have a considerable impact on business operations, which is evident in the literature (Singh \& El-kassar, 2019; Swaminathan, 2018; Zhao et al., 2017), they are mostly characterized as the core resource of the firm and not the capability. However, some scholars (Garmaki et al., 2016; Papadopoulos et al., 2017) have presented a strong argument characterizing BDPA as a capability that firms can build by integrating an information culture and strong intellect in their organizational structure. Utilization of strategic resources (Gupta \& George, 2016) like human skills not only complements technology, but also catalyzes the process of transforming techniques into core capabilities within an organization. A highly cultivated knowledge culture provides an ecosystem suitable for out-of-the-box thinking and can be seen in managerial decisions. Continuing education also helps strengthen niche technical skills. Dubey et al. (2019a) defined the constructs of operational performance while discussing the crucial need for managerial skills to leverage the best out of the available technology. A pool of intellectuals creates infinite possibilities if channeled in a targeted direction. However, this is not the first piece of research where the human quotient has been identified as a crucial component; previous research has provided in-depth knowledge of the linear relationships between technology like BDPA and performance at the organizational level (Dubey et al., 2019b; Wamba et al., 2018). However, no studies have revealed the contribution of human factors (managerial and technical skills) while converting a standard technology into an organizational core competitive capability and further transforming it into a more adaptive dynamic capability. Both managerial and technical skills affect the ongoing process of this development to a certain extent. Productive technical skills 
compliment BDPA technique during functioning and polished managerial skills facilitate rational decision making. Both skills strengthen overall business processes and guide them to the extent that they produce unexpected and incomparable results on critical business processes. Transparency and organizational support strengthen resources to mold the adaptive capability enough to confront the dynamic requirements or conditions. According to our first proposition, polished managerial skills of BDPA managers nurtured over time by an organization help them to be more capable of taking real-time decisions. This, in turn, serves to optimize the BDPA process and strengthen it to a level that facilitates the organization as a capability while achieving superior operational performance. The study therefore proposes its first hypothesis as follows:

H1: Managerial skills required in big data predictive analytics have a positive impact on the operational performance of an organization.

According to Amess \& Girma (2009), managerial skills are indicators of distinctive organizational resources and excellent assets that transforms stock resources into a valueloaded capability. The analogy between infrastructure, corporate skills and a firm's specific resources works as an in-house incubator; it helps an indigenously developing firm's core capabilities to be dynamic in nature. Xu \& Kim (2014) asserted the importance of managerial skills when creating business intelligence capabilities. Existing literature emphasizes the importance of managerial skills, but at the same time creates confusion about their direct effects on the market performance of an organization, which is an equally crucially coefficient. As this study is rooted in a dynamic resource-based view, managerial skills can facilitate technology while efficiently synthesizing and deciphering information (input and output) and helping to develop the technique into a capability. Technology acts as a core capability when it starts functioning as a mechanism of change and produces the factors that directly affect market performance. Dynamic managerial skills turn it into a capable resource when deploying BDPA, making it a capability whose output successfully represents market information. As final market performance is positively affected by results produced by BDPA, it starts to become a core capability within the organization while catering to the market demand for information. Managerial skills required for decision making play a crucial role in transforming BDPA outputs, yet there is no consideration for this in the available literature. We have tried to connect the dots to address the gap in the existing literature. This study thus proposes its next conjecture: 
H2: Managerial skills required in big data predictive analytics have a positive impact on the market performance of an organization.

Human capital is treated as a unique resource in the sense that it can be acquired but not imitated. Companies invest in their human capital, aspiring to leverage skills from the pool of intellect. Regardless of in-house hierarchy, in order to create a distinctive talent, companies incubate high-level technological learning and synchronize it with an elevated learning environment. The right blend of personal skills can transform resources into value and become a symbol of excellence for an organization. Polished managerial skills play an essential role at the time of execution and can build business intelligence capabilities $(\mathrm{Xu} \&$ Kim, 2014). Smart managerial skills benefit organizations in multiple ways when they produce impressive financial results. They save a hefty amount of a firm's assets by utilizing them in the best possible manner. Managerial intellectual capability helps a firm to acquire unique skills that can switch between over and under-utilization of resources. Financial performance is the bottom line of any business. Every organization invests a considerable amount while acquiring resources and seeks to obtain maximum output. Managerial skills in the analysis of information after the deployment of BDPA are crucial to the performance of this task. The possible number of solutions can be infinite as organizations are expected to acquire their resources and polish them strategically. Managerial skills polished over time help BDPA while accelerating the credibility of decision making and directly affecting the financial health of an organization while spreading the effects over other resources and assets. Organizations should hire competitive dynamic BDPA managers who possess competitive financial decision-making ability and strengthen the decision-making process while leveraging the BDPA. In a sense, managerial skills can improve BDPA as a capability, which can in turn positively affect the financial performance of an organization. The existing literature has asserted the impact of BDPA on superior organizational performance. However, the role of the dynamic human factor in developing BDPA into a capability for superior financial performance is still unclear. With this, we propose our next conjecture:

H3: Managerial skills required in big data predictive analytics have a positive impact on the financial performance of an organization. 
A great deal of literature available on BDPA supports the relationship between customer analytics and a firm's operational performance (Germann et al., 2014). For instance, big data predictive analysis enables firms to design management strategies by analyzing data sets (Brands, 2014).

Prominent scholars (Gupta \& George, 2016; Dubey et al., 2019a) have provided evidence of a direct relationship between BDPA and superior organizational performance (financial and operational). Previous studies (Swaminathan, 2018) have put forward the influential role of BDPA in driving sustainable and efficient operations. Recent studies (Mikalef \& Pateli, 2017) have treated BDPA as a component within an organization that adds value by elevating performance. Similarly, it is quite clear that operational performance directly or indirectly impacts a firm's market growth and helps in capturing significant market share. As superior organizational performance is not the goal in and of itself, organizations always race towards opportunities to capture more significant market share. There is thus a need to explore a different dimension of the literature to establish the relationship between organizational capabilities, i.e. technical skills, and the firm's operational performance. Bearing in mind the importance of establishing this relationship, the following research proposition has been framed:

H4: Technical skills required in big data predictive analytics have a positive impact on the operational performance of an organization.

Falkenreck \& Wagner (2017) studied the scope of the Internet of Things (IoT) in optimizing business operations based on the thinking that it would inject a new level of visibility and flexibility into the system. Supply chain sustainability gets a boost from the big data predictive analytics capability of a firm (Hazen et al., 2016), which is reflected in its superior organizational performance. Past scholars (Lu \& Ramamurthy, 2011; Wamba et al., 2017) have identified the link between information technology capability and a firm's outcome; but the way these technical skills affect the market at large still needs to be explored. Prescott (2014) advocated the importance of analytical thinking at all hierarchy levels in an organization. The current literature points towards the crucial presence of technical skills while executing BDPA. The extent to which it accommodates and affects market horizons needs to be studied. We feel that it is essential for firms to treat technical skills as a strategic tool that not only executes BDPA but also captures market sentiment and later helps in taking 
decisions that affect the market positioning of a firm and its performance. Therefore, we propose the next conjecture while trying to establish a direct relationship:

H5: Technical skills required in big data predictive analytics have a positive impact on the market performance of an organization.

A positive relationship can be seen between IT capabilities and a firm's business process and financial performance in the existing literature (Gibb et al., 2011). According to Dubey et al. (2019a), organizations that possess excellent BDPA capabilities will obtain a higher organizational performance, which directly effects its financial status in the business lexicon. Financial performance and economic performance have greater weight in overall performance and are directly linked (Mackey et al., 2007; Smith \& Tushman, 2005) to organizational capabilities. The inherent needs of managing a given profit level always affect the firm's expenditure decisions over resources or skills, and also limit the firm while building these capacities. Zhu et al. $(2008,2012)$ explored the platonic relationship between economic and operational performance. The framework conceptualized by Grover et al. (2018) strongly defined BDPA as a unique blend of resources to create true business value. Technical skills help while implementing BDPA so that all the processes are under financial control during deployment. We realize that the existing literature has not captured the actual effect of technical skills while developing BDPA into a capability and leading to higher financial performance. Not only do the right technical skills result in optimum performance, but they also positively affect the firm's balance sheet. Considering the gap, we therefore proposed our final conjecture, which links the effect of inertia due to specific technical skills on financial performance while developing BDPA as a core capability in an organization:

H6: Technical skills required in big data predictive analytics have a positive impact on the financial performance of an organization.

\section{Research Design}

\subsection{Survey}

The survey was given to employees working in Indian organizations that use high technology in their operations. The organizations use big data analytics as part of their decision-making procedure and these capabilities are developed in-house. The data was collected for the year 
2018 using an online questionnaire for respondents from diverse fields. We used the 5-point Likert Scale for our questionnaire (1- strongly disagree, 2- disagree, 3- neutral, 4- agree, and 5- strongly agree) (Dwivedi et al., 2013; Kim et al., 2009; Hair et al., 2013). To confirm the validity, reliability and appropriateness of the questionnaire, it was pre-tested by 20 respondents. The weblink of the questionnaire was distributed to approximately 1100 respondents, of which we received data from 290 respondents. After evaluating and examining all 290 responses, a total of 209 (19\% response rate) completely filled-out and usable responses were considered for the study. The data was standardized and there were no cases of missing data, zero variance or rank-related problems. Respondents from a broad agerange from 20-60 years and with diverse academic qualifications were considered for this study. Each segment of respondents from different age groups represents a different decisionmaking position, which creates a possibility of flexibility for the system; details are given in Table 1 below. Fifty percent (104) of the total 209 respondents belonged to the 20-30-yearold group and the lowest number of respondents were from the 41-60 age range. With regard to educational qualification, $61 \%$ (128) of the 209 respondents were post-graduates, whereas only $2 \%$ (5) of respondents held a PhD.

Table 1: Age group of employees and educational qualifications

\begin{tabular}{|c|c|c|c|c|}
\hline $\begin{array}{c}\text { Age-Group (in } \\
\text { years) }\end{array}$ & Graduate & $\begin{array}{c}\text { Post- } \\
\text { Graduate }\end{array}$ & PhD & Total \\
\hline $20-30$ & 41 & 63 & - & $\mathbf{1 0 4}$ \\
\hline $31-40$ & 25 & 54 & 3 & $\mathbf{8 2}$ \\
\hline $41-50$ & 10 & 10 & 2 & $\mathbf{2 2}$ \\
\hline $51-60$ & - & 1 & - & $\mathbf{1}$ \\
\hline Total & $\mathbf{7 6}$ & $\mathbf{1 2 8}$ & $\mathbf{5}$ & $\mathbf{2 0 9}$ \\
\hline
\end{tabular}

Table 2 shows the field of work of the respondents and their corresponding work experience. Respondents from nine different work fields were considered. The firm size differs according to the scale of the operations. It is clear from Table 2 that the respondents belong to diverse fields. Thirty-one percent (65) out of a total 209 respondents were from IT services/Software field, 16\% (34) of respondents belonged to Banking/Insurance/Financial services, and around $12 \%$ (26) of respondents were from the Consulting and Manufacturing fields in each case. Around $31 \%$ (64) of respondents had more than 10 years of work experience followed by $27 \%$ (56) of respondents with 5-10 years of experience. 
Table 2: Field of work of the employees and their work experience

\begin{tabular}{|c|c|c|c|c|c|c|}
\hline & \multicolumn{5}{|c|}{ Years of Work-Experience } & (1 - 3 \\
\hline Domain of Work & $\begin{array}{c}\text { Less than } \\
\mathbf{1} \text { year }\end{array}$ & $\begin{array}{c}\mathbf{3} \text { - } \\
\text { years }\end{array}$ & $\begin{array}{c}\mathbf{5}-\mathbf{1 0} \\
\text { years }\end{array}$ & $\begin{array}{c}\text { More than } \\
\mathbf{1 0} \text { years }\end{array}$ & $\begin{array}{c}\text { Tot } \\
\text { al }\end{array}$ \\
\hline $\begin{array}{c}\text { Banking/ Insurance/ } \\
\text { Financial Services }\end{array}$ & 5 & 5 & 9 & 9 & 6 & $\mathbf{3 4}$ \\
\hline $\begin{array}{c}\text { Construction/ Real Estate/ } \\
\text { Infrastructure }\end{array}$ & - & 2 & 1 & 3 & 5 & $\mathbf{1 1}$ \\
\hline Consulting & 2 & 8 & 3 & 4 & 9 & $\mathbf{2 6}$ \\
\hline Education/ Research & 1 & 6 & 6 & 4 & 2 & $\mathbf{1 9}$ \\
\hline Food \& Beverage & - & 1 & 2 & 1 & 1 & $\mathbf{5}$ \\
\hline Government & - & - & 3 & 2 & 3 & $\mathbf{8}$ \\
\hline IT Services/ Software & 1 & 7 & 15 & 20 & 22 & $\mathbf{6 5}$ \\
\hline Manufacturing & - & 2 & 2 & 6 & 15 & $\mathbf{2 5}$ \\
\hline Retail & 1 & 4 & 3 & 7 & 1 & $\mathbf{1 6}$ \\
\hline Total & $\mathbf{1 0}$ & $\mathbf{3 5}$ & $\mathbf{4 4}$ & $\mathbf{5 6}$ & $\mathbf{6 4}$ & $\mathbf{2 0 9}$ \\
\hline
\end{tabular}

Table 3 showcases the role of the respondents in their respective company/institution and the employee job level. Of the 209 respondents, 37\% (78) of respondents were Managers/Sr. Managers and 53\% (110) of respondents worked in a company/institute having more than 1000 employees. This study has considered diverse employee roles, especially those working at middle or senior level management, since employees at such levels have authoritative control in organizations, which in turn is crucial for implementing the strategies laid out by the top management of the organization.

Table 3: Role of employees in the company/institution and the number of employees

\begin{tabular}{|c|c|c|c|c|c|c|c|}
\hline & \multicolumn{6}{|c|}{ Number of Employees } & \\
\hline $\begin{array}{c}\text { Role in Company/ } \\
\text { Institution }\end{array}$ & $\begin{array}{c}\text { Less } \\
\text { than 10 }\end{array}$ & $\begin{array}{c}\mathbf{1 0}- \\
\mathbf{5 0}\end{array}$ & $\begin{array}{c}\mathbf{5 0}- \\
\mathbf{3 0 0}\end{array}$ & $\begin{array}{c}\mathbf{3 0 0}- \\
\mathbf{5 0 0}\end{array}$ & $\begin{array}{c}\mathbf{5 0 0}- \\
\mathbf{1 0 0 0}\end{array}$ & $\begin{array}{c}\text { More than } \\
\mathbf{1 0 0 0}\end{array}$ & $\begin{array}{c}\text { Tot } \\
\text { al }\end{array}$ \\
\hline $\begin{array}{c}\text { After-Sales Support } \\
\text { Executive }\end{array}$ & - & 1 & - & 1 & - & 2 & $\mathbf{4}$ \\
\hline AVP/VP/ EVP & - & 1 & 4 & 1 & 2 & 7 & $\mathbf{1 5}$ \\
\hline Consultant & 7 & 4 & 3 & 4 & 4 & 14 & $\mathbf{3 6}$ \\
\hline
\end{tabular}




\begin{tabular}{|c|c|c|c|c|c|c|c|}
$\begin{array}{c}\text { Corporate Finance } \\
\text { Executive/ Analyst }\end{array}$ & - & 2 & 1 & 2 & 1 & 11 & $\mathbf{1 7}$ \\
\hline Director/ CEO/ Founder & 2 & 6 & - & 1 & - & 1 & $\mathbf{1 0}$ \\
\hline Engineer & 1 & 2 & 3 & 2 & 7 & 26 & $\mathbf{4 1}$ \\
\hline Manager/ Sr. Manager & 2 & 4 & 7 & 7 & 11 & 47 & $\mathbf{7 8}$ \\
\hline $\begin{array}{c}\text { Sales/ Marketing } \\
\text { Executive }\end{array}$ & 1 & - & 1 & 2 & 2 & 2 & $\mathbf{8}$ \\
\hline Total & $\mathbf{1 3}$ & $\mathbf{2 0}$ & $\mathbf{1 9}$ & $\mathbf{2 0}$ & $\mathbf{2 7}$ & $\mathbf{1 1 0}$ & $\mathbf{2 0 9}$ \\
\hline
\end{tabular}

\subsection{Data Analysis}

Various disciplines of management science like marketing, strategic management, psychology, etc., have deployed Structural Equation Modeling (SEM) for data analysis (Astrachan et al., 2014). There are two types of SEM techniques: one is Covariance-Based (CB) SEM and the other is Partial Least Squares (PLS)-based SEM (Hair et al., 2013). When the relationship between dependent and independent variables is exploratory in nature, PLSSEM is more suitable as opposed to CB-SEM for confirmatory studies (Hair et al., 2013; Henseler et al., 2014). Furthermore, normally distributed data is not required for the PLSSEM (Hair et al., 2011; Kock, 2015). Since the objective of this study is exploratory in nature, PLS-SEM is the more suitable technique for data analysis. WarpPLS 6.0 has been employed to perform the PLS-SEM. The efficiency of the parameter estimation becomes higher when PLS-SEM is used (Hair et al., 2013). Table 4 below, shows the model-fit and quality indices (Kock, 2015). Average path coefficient (APC), Average R-squared (ARS) and Average block VIF (AVIF) are all significant. The P-value is less than 0.05 and the AVIF is 2.240 , which are in the ideal range.

Table 4: Model fit and quality indices

\begin{tabular}{|c|c|}
\hline Average path coefficient (APC) & $0.196, \mathrm{P}<0.001$ \\
\hline Average R-squared (ARS) & $0.441, \mathrm{P}<0.001$ \\
\hline Average block VIF (AVIF) & 2.240, acceptable if $<=5$, ideally $<=3.3$ \\
\hline
\end{tabular}


The correctness of the research model is given by the causality assessment indices in Table 5 . All the causality assessment indices (Simpson's paradox ratio (SPR), R-squared contribution ratio (RSCR), and Statistical suppression ratio (SSR)) are within acceptable range.

Table 5: Causality assessment indices

\begin{tabular}{|c|c|}
\hline Simpson's paradox ratio (SPR) & 0.917, acceptable if $>=0.7$, ideally $=1$ \\
\hline R-squared contribution ratio (RSCR) & 0.999, acceptable if $>=0.9$, ideally $=1$ \\
\hline Statistical suppression ratio (SSR) & 1.000, acceptable if $>=0.7$ \\
\hline
\end{tabular}

The internal validity of the scale is measured using Cronbach's alpha and composite reliability, with an accepted value of 0.7 or higher (Nunnally \& Bernstein, 1994; Tellis et al., 2009). Cronbach's alpha and composite reliability coefficients calculated for this study reflect the strong reliability of the instrument, and coefficients are all beyond the threshold value of 0.7 as shown in Table 6. The average variance extracted (AVE) is more than 0.5 (accepted value) (Hair et al., 2005), also shown in Table 6 below. Multicollinearity among the variables is measured by Variance Inflation Factor (VIF), which for this study is in the acceptable value of less than 5 for each variable (Kock \& Lynn, 2012).

Table 6: Latent variable coefficients

\begin{tabular}{|c|c|c|c|c|c|}
\hline & MS & TS & OP & MP & FP \\
\hline R-squared coefficients & - & - & 0.518 & 0.479 & 0.327 \\
\hline Adjusted R-squared coefficients & - & - & 0.509 & 0.468 & 0.313 \\
\hline Composite reliability coefficients & 0.966 & 0.949 & 0.937 & 0.925 & 0.964 \\
\hline Cronbach's alpha coefficients & 0.966 & 0.949 & 0.939 & 0.925 & 0.965 \\
\hline $\begin{array}{c}\text { Average variances extracted } \\
\text { (AVE) }\end{array}$ & 0.85 & 0.788 & 0.79 & 0.754 & 0.871 \\
\hline Variance inflation factors (VIF) & 4.025 & 3.865 & 3.746 & 3.015 & 1.818 \\
\hline
\end{tabular}

The discriminant validity test is used to identify the relationship of indicators with the constructs given in Table 7 . The square root of the average variance is more than the construct correlations (Fornell \& Larcker, 1981).

Table 7: Correlations among latent variables with square root of AVEs Note: Square roots of average variances extracted (AVEs) shown on diagonal. 


\begin{tabular}{|c|c|c|c|c|c|}
\hline & MS & TS & OP & MP & FP \\
\hline MS & $\mathbf{0 . 9 2 2}$ & & & & \\
\hline TS & 0.847 & $\mathbf{0 . 8 8 8}$ & & & \\
\hline OP & 0.694 & 0.66 & $\mathbf{0 . 8 8 9}$ & & \\
\hline MP & 0.657 & 0.651 & 0.8 & $\mathbf{0 . 8 6 8}$ & \\
\hline FP & 0.531 & 0.534 & 0.657 & 0.55 & $\mathbf{0 . 9 3 3}$ \\
\hline
\end{tabular}

The result and the supported/unsupported hypotheses are given in Table 8 below.

Table 8: Results of hypothesis testing

\begin{tabular}{|c|c|c|}
\hline Hypothesis & $\beta$ and $p$-value & Supported or Not-Supported \\
\hline $\begin{array}{l}\text { H1: Managerial skills required in big data } \\
\text { predictive analytics has a positive impact } \\
\text { on the operational performance of an } \\
\text { organization }\end{array}$ & $\beta=0.46 p<.01$ & Supported \\
\hline $\begin{array}{l}\text { H2: Managerial skills required in big data } \\
\text { predictive analytics has a positive impact } \\
\text { on the market performance of an } \\
\text { organization }\end{array}$ & $\beta=0.35 p<.01$ & Supported \\
\hline $\begin{array}{l}\text { H3: Managerial skills required in big data } \\
\text { predictive analytics has a positive impact } \\
\text { on the financial performance of an } \\
\text { organization }\end{array}$ & $\beta=0.31 \mathrm{p}<.01$ & Supported \\
\hline $\begin{array}{l}\text { H4: Technical skills required in big data } \\
\text { predictive analytics has a positive impact } \\
\text { on the organizational performance of an } \\
\text { organization }\end{array}$ & $\beta=0.28 p<.01$ & Supported \\
\hline $\begin{array}{l}\text { H5: Technical skills required in big data } \\
\text { predictive analytics has a positive impact } \\
\text { on the market performance of an } \\
\text { organization }\end{array}$ & $\beta=0.35 p<.01$ & Supported \\
\hline $\begin{array}{l}\text { H6: Technical skills required in big data } \\
\text { predictive analytics has a positive impact } \\
\text { on the financial performance of an } \\
\text { organization }\end{array}$ & $\beta=0.27 p<.01$ & Supported \\
\hline
\end{tabular}

Figure 1 below depicts the dependency of organizational performance on BDPA capabilities.

Based on the results, the study proposes a research framework that shows the direct relationship between managerial and technical skills and the variables of organizational performance (operational, market and financial). 


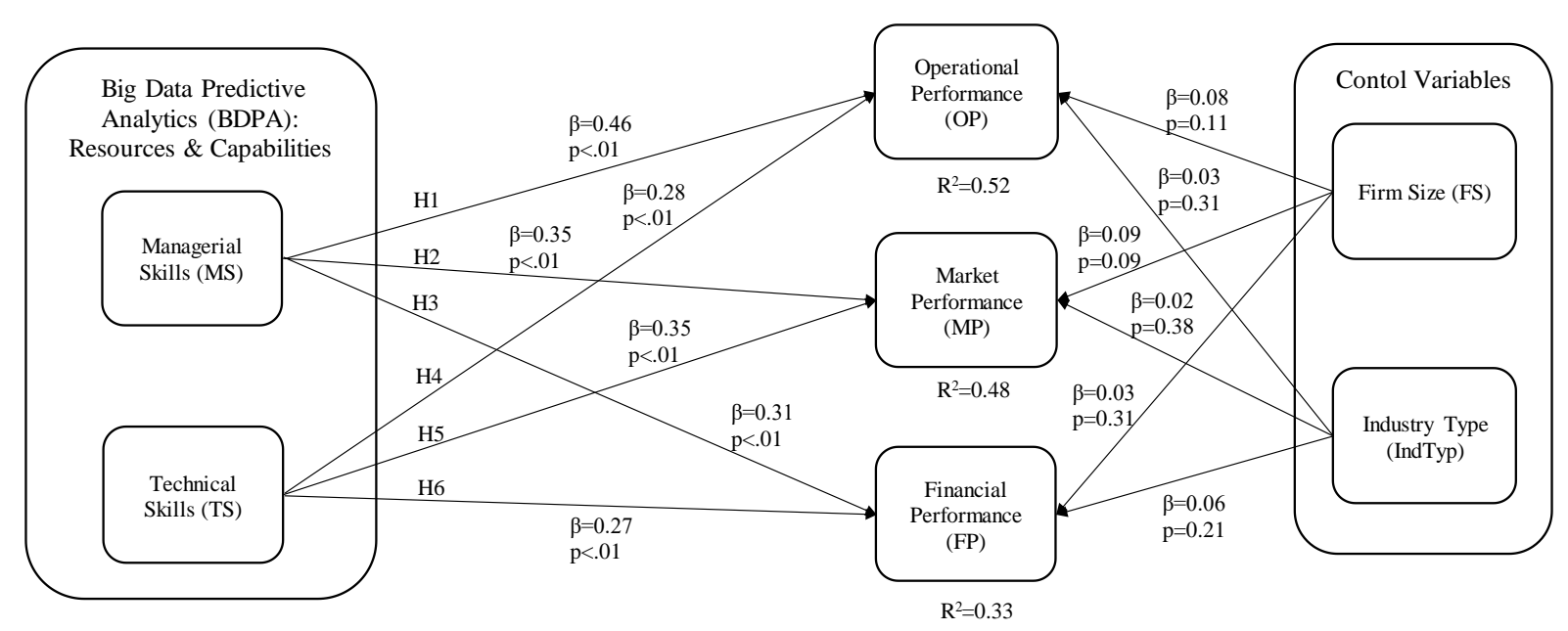

Fig. 1: Theoretical Model with PLS-SEM Analysis

\section{Discussion}

This section sheds light on the findings of this study by validating the research propositions. Gupta \& George (2016) and Wamba et al. (2017) have advocated the use of BDPA as an organizational capability and Papadopoulos et al. (2017) has showcased that these BDPA capabilities can be employed in niche areas to better understand disaster resilience in supply chains so as to promote sustainability. In an era of data deluge, when organizations treat themselves to new technological advancements and skills, market share is also worth mentioning. A firm's overall credibility is a dependent function of its resources and capabilities, which is reflected in the market performance. Managing a volatile market is a challenge for a firm that allows no room for error. From the beginning, this whole line of thought is setup on the backdrop of DCV (Barney, 1991), which motivates organizations to acquire strategic resources. These resources can help to build up flexible and dynamic capabilities to confront abrupt changes in demand and supply. This study seeks to demonstrate a positive relationship between organizational capability (BDPA in this case) and organizational performance. The existing literature also follows the weight of operational and economic performance. Our first hypothesis $\mathrm{H} 1$ is based on the establishment of a relationship between managerial skills, which is one of two crucial components of BDPA capability, and the operational performance of the firm, which is further verified and supported empirically. $\mathrm{H} 2$ further strengthens the observation that managerial skills are not only an inherent part of the organizational structure, but they help in expanding firms' location and value in the market, thus helping them acquire a larger market share. Following this, H3 shows the importance of managerial skills in developing BDPA into a distinct capability for performing well not only in term of sales but also in financial terms (financial 
performance). This study also considered other crucial skills (technical skill) for achieving superior performance. $\mathrm{H} 4$ connects technical skills with operational performance. The above relationship has been proven positive in light of recent results.

Similarly, H5 and H6 must be accepted following an empirical investigation of the data, and successfully state the positive impact of technical skills on both market and financial performance when developing BDPA. Fig. 1 and Table 8 show the acceptance of all six hypotheses, demonstrating that all the $p$ values are less than 0.05 , which means 95 percent of the time, the dependent variable, i.e. operational performance, market performance and financial performance was positively affected by the enablers (managerial skills and technical skills) of BDPA. This study also investigated the effect of control variables, i.e. firm size and industry type, on all three performance indicators (operational, market and financial). This relationship stands out as negative after empirical investigation, as the $p$-values are 0.11 , $0.31,0.09,0.38,0.31$ and 0.21 , respectively, which are not considered significant. A fuller understanding of the results shows that firm size and industry type does not affect superior organizational performance, and this remains valid almost 95 percent of the time. Our contribution to the literature and industry further provides two explanations concerning the theoretical contribution, which is a significant addition to the existing academic literature and helps extend the understanding of the concept by filling a gap in the existing literature. Also, it gives scholars a new direction to take up future research. The second part, managerial contribution, explains the way managers follow the path of tested knowledge and create a whole new arena of possibilities. This study places significant and noticeable emphasis on managerial implication, which helps organizations to understand the importance of big data predictive analysis (BDPA) capabilities (managerial skills and technical skills) in the firm's overall performance.

\subsection{Theoretical Contributions}

This study attempts to link organizational capability to overall performance. Considering BDPA as one of the capabilities with the highest potential, especially for technologyintensive firms, the specific importance of skills/resources required by the organization has been studied. This research helps to build robust and distinct dynamic BDPA capabilities that make the system responsive enough to face abrupt changes and market volatility. Despite growing interest in big data and predictive analysis, limited literature is available in which scholars have shown some of the relevant findings. Furthermore, dynamic capabilities 
(Wamba et al., 2017) have shown the potential to elevate performance to a desired level. A whole new array of possibilities for big data predictive analysis have opened up and need to be investigated. The classification of BDPA capabilities given by Gupta \& George (2016) helps users focus on the weak functional capabilities in an organization. Giannoccaro (2018) took it a step further and talked about the importance of cognitive analytical skills, which is a crucial aspect of managerial skills required by decision makers. Martin \& Bachrach (2018) argued that dynamic managerial capability helps a firm to network, which affects superior organizational performance overall. Most of the previous findings shed light on the direct relationship between BDPA, which can be a capability resource, and organizational performance. There is no evidence in the literature that defines the importance and contribution of selected strategic resources (human factor) while developing a dynamic competency for sustainable and superior organizational performance. Adding a new dimension to previous work on operational performance (Dubey et al., 2019a) that promotes the direct link between BDPA capabilities and financial as well as operational performance of an organization under the resource-based view, our study extends into the downstream relationship while defining human resources as an important ally (technical and managerial skills), thus completing the whole chain of BDPA as a capability development process from strategic resources that are dynamic in nature overall to achieving all of the dimensions of performance. As this study is rooted in the dynamic capability view (DCV), Barney (1991) continuously encourages organizations to strengthen their technical and managerial skill sets, which can add to their BDPA capabilities. Secondly, nothing in the study reveals how the fundamental functions of superior organizational performance (operational and financial) (Gupta \& George, 2016) actually affect the relationship between the organization's data analytical capability (BDPA) and market performance (Schoenherr, 2012; Zhu \& Sarkis, 2004; Zhu et al., 2005; Zsidisin \& Hendrick, 1998). In addition, there is no evidence in the literature about the connection between superior organizational performance (financial, operational) and BDPA capabilities and market performance. This study also includes control variables within its scope. It is worth mentioning that no evidence can be found in the literature that addresses the effect of control variables such as firm size and industry type on overall superior organizational performance. The study enriches the literature and shows the negative effect of the overall size of the firm and specific field of industry on superior organizational performance, demonstrating that the study can be deployed throughout operational organizations regardless of their size and type. The study strongly asserts that firms that are willing to initiate operational change to better nurture their resources will be 
rewarded in capability, which can help them to reap superior organizational performance in all three of its facets. Furthermore, it is not certain that size and industry type will act as constraints. The results after analysis show that all of the hypotheses considered for the study are accepted. This relationship is crucial considering the dynamic competitive environment. This unfolds into a crucial relationship between BDPA capabilities and overall organizational performance. Finally, the literature as well as organizations benefit from the findings of the research finding and the concept that there is a convincing relationship between big data predictive analysis (BDPA) and sustainable market performance.

\subsection{Managerial Implications}

The current study shows a clear awareness of the importance of different skill sets that organizations need to acquire over time in order to leverage them during capacity building. The overwhelming amount of data often pressures firms to acquire the latest technology for tech-driven operations, but they do not actually utilize it optimally due to a lack of required skill sets/indigenous resources. Furthermore, underutilization of resources adds to the financial liabilities of organizations and poor market share can be the resulting collateral damage. From the industrial market viewpoint, both opportunity costs and sunk costs are wasted, limiting the growth of an organization. The purpose of this study is to explain the importance of crucial resources (data, technical skills, managerial skills) for big data predictive analytics discussed by previous researchers (Schoenherr, 2012; Zhu \& Kraemer, 2005; Zhu \& Sarkis, 2004; Zsidisin \& Hendrick, 1998) so that this will be taken up by the management for critical consideration. These resources help smooth out the challenges (Mikalef \& Pateli, 2017; Vidgen et al., 2017) faced by organizations during implementation of BDPA in organizational operations.

The findings of this study give a clear picture of the vital role of human skills in building BDPA capability. With reference to the results of this study, it has now been empirically tested that good BDPA capability can give a firm an edge over the others and the potential to capture a much larger market share via performance. Bolstering the work of Mackey et al. (2007), the current study demonstrates the influence of BDPA capability when building a profit structure that can actually regulate the market in the long term. The findings also help organizations to learn and think in an oriented way so that they can focus more on acquiring the right personnel and nurturing the technical as well as managerial capabilities they utilize in their analytical culture. Data-driven decisions often prove to be a winning tool in the market, but they are even stronger when driven by technical analysis and decisive 
management skills. The results of our study help managers confronted with non-productive operations even after investing huge amounts to acquire resources with the hope of building the capability in its various forms. Firms can now invest in the right talent by deploying focused strategies and nurturing the data culture, which can act as a BDPA catalyst and enhance its capability to respond in the most critical situations.

Our results further help managers not to be overly concerned with size and type of industry when developing an individual firms' capability, as it will not positively affect the firm's overall performance. Managers need to think in a way that enables organizations to balance their financial performance, keeping control of financial expenditures as well as adopting green and flexible technologies to achieve higher levels of operational performance, which leads to overall gains in market share.

\section{Limitations and Future Scope of the Research}

Though this study investigates new dimensions in BDPA, it also has some limitations. One of the first limitations is that the data has been gathered at a single point of time, and could go further by collecting longitudinal data. A longitudinal study would enrich our understanding about the causal relationship between the constructs (Guide \& Ketokivi, 2015).

Secondly, the current study puts emphasis on organizations that are technologically advanced in their operations and can easily build BDPA facilities and nurture their environment. This is a bigger challenge for organizations that are not quite as technically competent and that are skeptical of building and outsourcing BDPA. Furthermore, their longterm motivation differs when choosing to build or outsource the BDPA facility. It would be interesting to see that how human capital working in non-high-tech organizations would complement or create constraints in BDPA capabilities.

Finally, the demographic constraint of the sample does not make it possible to generalize the findings. The data collected for this study is from a developing economy (India), and it would be worthwhile to compare the results with data collected from organizations in a developed economy. The same result can be applied to the organizations of developed economies, and it would be interesting to study the extent of market performance's effect on the relationship between BDPA capability and sustainable performance. We therefore anticipate that future studies will be able to include data from different industries and a wider range of locations.

\section{Conclusion}


Despite the hype around the constant growth of big data, the mechanisms and conditions through which innovation can be enhanced remain an under-explored part of the research. To address this gap, this study is built on two core aspects of big data: information and big data analytics capability. Supported by the DCV and past studies in the field of information systems, we examine the dependencies that characterize the relationship between information governance and a firm's big data predictive analytics capabilities. We examined primary survey data from 209 high-level executives and used PLS-SEM analysis to investigate our hypothetical relationships. By doing so, we add to the emerging literature on the importance of information culture in the big data era, and the criticality of establishing a robust scheme for maturing a firm's big data analytics capability, as well as for harnessing insight and transforming it into action. While there is significant anecdotal evidence concerning the role of BDPA on accelerating a firm's innovative capability, there is very limited theoretically grounded research to verify such a relationship.

Based on the concept of the Dynamic Capability View, we have conceptualized big data predictive analysis as a distinctive capability that can positively affect market performance. Empirical testing in this study provides proof that human skills (managerial and technical skills) are game-changing and will add analytical traits to the organization. Also, our study shows that firm size and industry type possess zero or minimal effect on a firm's overall performance. New options will open up for industrial management, which can lead users as well as academics to further deploy and explore BDPA and its capability in the future. In addition, this study helps the industrial and marketing management audience to understand how a firm can help its smart capabilities to manage their operations as well as to impact the market in the age of industry 4.0. This study is a useful contribution to research in BDPA and its direct effect on financial, operational and market performance (Gupta \& George, 2016). Finally, our study offers many research opportunities based on our limitations, which can be explored in the future with a sample of different non-high-tech industries.

\section{Appendix A}

Operationalization of Constructs

\begin{tabular}{|c|c|c|}
\hline Latent Variable & Indicator & Measurement Constructs \\
\hline Big Data Predictive Analytics & & Managerial Skills (MS) \\
\hline
\end{tabular}




\begin{tabular}{|c|c|c|}
\hline \multirow{11}{*}{$\begin{array}{l}\text { Gupta and George, 2016; } \\
\text { Dubey et al., 2019a }\end{array}$} & MS1 & $\begin{array}{l}\text { Big data analytics managers are able to } \\
\text { work with functional managers, suppliers, } \\
\text { and customers }\end{array}$ \\
\hline & MS2 & $\begin{array}{l}\text { Big data analytics managers are able to } \\
\text { coordinate big data-related activities }\end{array}$ \\
\hline & MS3 & $\begin{array}{l}\text { Big data analytics managers are able to } \\
\text { anticipate the future business needs }\end{array}$ \\
\hline & MS4 & $\begin{array}{l}\text { Big data analytics managers have a good } \\
\text { sense of where to apply big data }\end{array}$ \\
\hline & MS5 & $\begin{array}{l}\text { Big data analytics managers are able to } \\
\text { understand and evaluate the output } \\
\text { extracted from big data }\end{array}$ \\
\hline & \multicolumn{2}{|r|}{ Technical Skills (TS) } \\
\hline & TS1 & Big data analytics training to employees \\
\hline & TS2 & $\begin{array}{l}\text { Hire new employees that already have the } \\
\text { big data analytics skills }\end{array}$ \\
\hline & $\mathrm{TS} 3$ & $\begin{array}{l}\text { Big data analytics staff has the right skills } \\
\text { to accomplish their jobs successfully }\end{array}$ \\
\hline & TS4 & $\begin{array}{l}\text { Big data analytics staff has suitable } \\
\text { education to fulfill their jobs }\end{array}$ \\
\hline & TS5 & $\begin{array}{l}\text { Big data analytics staff holds suitable work } \\
\text { experience to accomplish their jobs } \\
\text { successfully }\end{array}$ \\
\hline \multirow{4}{*}{$\begin{array}{l}\text { Operational Performance } \\
\text { (OP) }\end{array}$} & OP1 & $\begin{array}{l}\text { Productivity has exceeded compared to } \\
\text { competitors }\end{array}$ \\
\hline & OP2 & $\begin{array}{l}\text { Profit rate has exceeded compared to } \\
\text { competitors }\end{array}$ \\
\hline & OP3 & $\begin{array}{l}\text { Return on investment (ROI) has exceeded } \\
\text { compared to competitors }\end{array}$ \\
\hline & OP4 & $\begin{array}{l}\text { Sales revenue has exceeded compared to } \\
\text { competitors }\end{array}$ \\
\hline \multirow{2}{*}{ Financial Performance (FP) } & FP1 & Average Return on Investment \\
\hline & FP2 & Average Profit \\
\hline \multirow{2}{*}{ Gupta and George, 2016} & FP3 & Profit Growth \\
\hline & FP4 & Average Return on Sales \\
\hline \multirow{2}{*}{$\begin{array}{c}\text { Market Performance (MP) } \\
\text { Gupta and George, } 2016\end{array}$} & MP1 & $\begin{array}{c}\text { Exploring new markets more quickly than } \\
\text { competitors }\end{array}$ \\
\hline & MP2 & $\begin{array}{l}\text { Introducing new products or services into } \\
\text { the market faster than competitors }\end{array}$ \\
\hline
\end{tabular}




\begin{tabular}{|c|c|c|} 
& MP3 & $\begin{array}{c}\text { Success rate of new products or services } \\
\text { has been higher than competitors }\end{array}$ \\
\cline { 2 - 3 } & MP4 & $\begin{array}{c}\text { Market share has exceeded that of } \\
\text { competitors }\end{array}$ \\
\hline
\end{tabular}




\section{Appendix B}

\section{Combined loadings and cross-loadings}

Note: Loadings are unrotated and cross-loadings are oblique-rotated. Standard errors (SES) and p-values are for loadings. $P$-values $<0.05$ are desirable for reflective indicators.

\begin{tabular}{|c|c|c|c|c|c|l|c|c|}
\hline & MS & TS & OP & MP & FP & Type & SE & P value \\
\hline MS1 & $\mathbf{0 . 8 9 8}$ & -0.096 & 0.084 & -0.102 & 0.046 & Reflective & 0.058 & $<0.001$ \\
\hline MS2 & $\mathbf{0 . 9 2 4}$ & -0.147 & 0.181 & -0.17 & -0.015 & Reflective & 0.058 & $<0.001$ \\
\hline MS3 & $\mathbf{0 . 9 3}$ & -0.157 & -0.059 & -0.032 & 0.046 & Reflective & 0.058 & $<0.001$ \\
\hline MS4 & $\mathbf{0 . 9 3 8}$ & -0.121 & -0.064 & 0.078 & 0.009 & Reflective & 0.058 & $<0.001$ \\
\hline MS5 & $\mathbf{0 . 9 2}$ & -0.007 & -0.022 & 0.005 & -0.026 & Reflective & 0.058 & $<0.001$ \\
\hline TS1 & -0.099 & $\mathbf{0 . 8 4 1}$ & 0.146 & -0.079 & -0.138 & Reflective & 0.059 & $<0.001$ \\
\hline TS2 & -0.177 & $\mathbf{0 . 8 5 8}$ & -0.063 & 0.006 & 0.011 & Reflective & 0.059 & $<0.001$ \\
\hline TS3 & -0.069 & $\mathbf{0 . 9 2 9}$ & 0.039 & 0.009 & -0.061 & Reflective & 0.058 & $<0.001$ \\
\hline TS4 & 0.022 & $\mathbf{0 . 8 9 7}$ & -0.122 & -0.081 & 0.106 & Reflective & 0.058 & $<0.001$ \\
\hline TS5 & -0.042 & $\mathbf{0 . 9 1 2}$ & -0.085 & 0.016 & -0.01 & Reflective & 0.058 & $<0.001$ \\
\hline OP1 & 0.106 & -0.046 & $\mathbf{0 . 8 2}$ & -0.215 & -0.126 & Reflective & 0.059 & $<0.001$ \\
\hline OP2 & -0.066 & -0.016 & $\mathbf{0 . 9 3 5}$ & -0.024 & -0.029 & Reflective & 0.058 & $<0.001$ \\
\hline OP3 & -0.211 & 0.178 & $\mathbf{0 . 9 0 2}$ & -0.122 & -0.051 & Reflective & 0.058 & $<0.001$ \\
\hline OP4 & -0.056 & -0.096 & $\mathbf{0 . 8 9 4}$ & -0.062 & 0.072 & Reflective & 0.058 & $<0.001$ \\
\hline MP1 & -0.053 & 0.014 & -0.117 & $\mathbf{0 . 8 6 5}$ & 0.051 & Reflective & 0.059 & $<0.001$ \\
\hline MP2 & 0.106 & -0.119 & -0.167 & $\mathbf{0 . 8 8 2}$ & -0.039 & Reflective & 0.059 & $<0.001$ \\
\hline MP3 & -0.045 & 0.011 & -0.113 & $\mathbf{0 . 9 1 2}$ & -0.059 & Reflective & 0.058 & $<0.001$ \\
\hline MP4 & 0.01 & -0.202 & 0.165 & $\mathbf{0 . 8 1 2}$ & 0.041 & Reflective & 0.059 & $<0.001$ \\
\hline FP1 & 0.029 & -0.114 & -0.046 & 0.059 & $\mathbf{0 . 8 9 9}$ & Reflective & 0.058 & $<0.001$ \\
\hline FP2 & -0.074 & 0.094 & -0.14 & 0.064 & $\mathbf{0 . 9 4 3}$ & Reflective & 0.058 & $<0.001$ \\
\hline FP3 & -0.075 & 0.072 & -0.041 & -0.003 & $\mathbf{0 . 9 4 1}$ & Reflective & 0.058 & $<0.001$ \\
\hline FP4 & -0.029 & 0.039 & -0.123 & 0.044 & $\mathbf{0 . 9 5}$ & Reflective & 0.058 & $<0.001$ \\
\hline
\end{tabular}




\section{Appendix C}

\section{Indicator weights}

\begin{tabular}{|c|c|c|c|c|c|c|c|}
\hline & MS & TS & OP & MP & FP & SE & p-value \\
\hline MS1 & 0.143 & & & & & 0.067 & 0.017 \\
\hline MS2 & 0.231 & & & & & 0.066 & $<0.001$ \\
\hline MS3 & 0.243 & & & & & 0.066 & $<0.001$ \\
\hline MS4 & 0.253 & & & & & 0.066 & $<0.001$ \\
\hline MS5 & 0.175 & & & & & 0.067 & 0.005 \\
\hline TS1 & & 0.124 & & & & 0.068 & 0.034 \\
\hline TS2 & & 0.15 & & & & 0.067 & 0.013 \\
\hline TS3 & & 0.33 & & & & 0.065 & $<0.001$ \\
\hline TS4 & & 0.197 & & & & 0.067 & 0.002 \\
\hline TS5 & & 0.257 & & & & 0.066 & $<0.001$ \\
\hline OP1 & & & 0.148 & & & 0.067 & 0.015 \\
\hline OP2 & & & 0.34 & & & 0.065 & $<0.001$ \\
\hline OP3 & & & 0.278 & & & 0.066 & $<0.001$ \\
\hline OP4 & & & 0.28 & & & 0.066 & $<0.001$ \\
\hline MP1 & & & & 0.21 & & 0.066 & $<0.001$ \\
\hline MP2 & & & & 0.309 & & 0.065 & $<0.001$ \\
\hline MP3 & & & & 0.398 & & 0.064 & $<0.001$ \\
\hline MP4 & & & & 0.135 & & 0.067 & 0.023 \\
\hline FP1 & & & & & 0.151 & 0.067 & 0.013 \\
\hline FP2 & & & & & 0.285 & 0.066 & $<0.001$ \\
\hline FP3 & & & & & 0.26 & 0.066 & $<0.001$ \\
\hline FP4 & & & & & 0.332 & 0.065 & $<0.001$ \\
\hline
\end{tabular}

\section{References}

Akter, S., Wamba, S. F., Gunasekaran, A., Dubey, R., \& Childe, S. J. (2016). How to improve firm performance using big data analytics capability and business strategy alignment? International Journal of Production Economics, 182, 113-131. Elsevier.

Amess, K., \& Girma, S. (2009). Do Stock Markets Value Efficiency? Scottish Journal of Political Economy, 56(3), 321-331.

Astrachan, C. B., Patel, V. K., \& Wanzenried, G. (2014). A comparative study of CB-SEM and PLS-SEM for theory development in family firm research. Journal of Family Business Strategy, 5(1), 116-128.

Azeroual, O., Saake, G., \& Schallehn, E. (2018). Analyzing data quality issues in research information systems via data profiling. International Journal of Information 
Management, 41(March), 50-56. Elsevier.

Barney, J. (1991). Firm resources and sustained competitive advantage. Journal of Management, 17(1), 99-120.

Barratt, M., \& Oke, A. (2007). Antecedents of supply chain visibility in retail supply chains: A resource-based theory perspective. Journal of Operations Management, 25(6), 12171233.

Brandon-Jones, E., Squire, B., Autry, C., \& Petersen, K. J. (2014). A Contingent ResourceBased Perspective of Supply Chain Resilience and Robustness. Journal of Supply Chain Management.

Brands, K. C. M. A. (2014). Big data and business intelligence for management accountants. Strategic Finance, 95(64-65).

Cao, G., \& Duan, Y. (2014). A path model linking business analytics, data-driven culture, and competitive advantage. In: European conference on information systems (ECIS). Proceedings of the European Conference on Information Systems (ECIS). Tel Aviv: AIS Electronic Library (AISeL).

Chen, H., Chiang, R. H., \& Storey, V. C. (2012). Business Intelligence and Analytics: From Big Data to Big Impact. MIS Quarterly, 36(4), 1165-1188.

Davenport, T. (2014). Big data at work: dispelling the myths, Uncovering the Opportunities. Harvard Business Review Press.

de Camargo Fiorini, P., Seles, B. M. R. P., Jabbour, C. J. C., Mariano, E. B., \& de Sousa Jabbour, A. B. L. (2018). Management theory and big data literature: From a review to a research agenda. International Journal of Information Management, 43, 112-129

Duan, Y., Edwards, J. S., \& Dwivedi, Y. K. (2019). Artificial intelligence for decision making in the era of Big Data-evolution, challenges and research agenda. International Journal of Information Management, 48, 63-71.

Duan, L., \& Xiong, Y. (2015). Big data analytics and business analytics. Journal of Management Analytics, 2(1), 1-21.

Dubey, R., Gunasekaran, A., Childe, S. J., Papadopoulos, T., Luo, Z., Wamba, S. F., \& Roubaud, D. (2019a). Can big data and predictive analytics improve social and environmental sustainability? Technological Forecasting and Social Change, 144, 534545.

Dubey, Rameshwar, Gunasekaran, A., Childe, S. J., Roubaud, D., Fosso Wamba, S., Giannakis, M., \& Foropon, C. (2019b). Big data analytics and organizational culture as complements to swift trust and collaborative performance in the humanitarian supply 
chain. International Journal of Production Economics, 210, 120-136.

Dwivedi, Y. K., Hughes, L., Ismagilova, E., Aarts, G., Coombs, C., Crick, T., ... \& Galanos, V. (2019). Artificial Intelligence (AI): Multidisciplinary perspectives on emerging challenges, opportunities, and agenda for research, practice and policy. International Journal of Information Management. DoI: https://doi.org/10.1016/j.ijinfomgt.2019.08.002

Dwivedi, Y. K., Janssen, M., Slade, E. L., Rana, N. P., Weerakkody, V., Millard, J., Hidders, J., et al. (2017). Driving innovation through big open linked data (BOLD): Exploring antecedents using interpretive structural modelling. Information Systems Frontiers, 19(2), 197-212. Information Systems Frontiers.

Dwivedi, Y. K., Wastell, D., Laumer, S., Henriksen, H. Z., Myers, M. D., Bunker, D., Elbanna, A., et al. (2015). Research on information systems failures and successes: Status update and future directions. Information Systems Frontiers, 17(1), 143-157.

Dwivedi, Y. K., Kapoor, K. K., Williams, M. D., \& Williams, J. (2013). RFID systems in libraries: An empirical examination of factors affecting system use and user satisfaction. International Journal of Information Management, 33(2), 367-377.

Eisenhardt, K. M., \& Martin, J. A. (2000). Dynamic capabilities: what are they? Strategic Management Journal, 21, 1105-1121.

Erevelles, S., Fukawa, N., \& Swayne, L. (2016). Big Data consumer analytics and the transformation of marketing. Journal of Business Research, 69(2), 897-904.

Falkenreck, C., \& Wagner, R. (2017). The Internet of Things - Chance and challenge in industrial business relationships. Industrial Marketing Management, 66, 181-195. Elsevier.

Fatorachian, H., \& Kazemi, H. (2018). A critical investigation of Industry 4.0 in manufacturing: theoretical operationalisation framework. Production Planning and Control, 29(8), 633-644. Taylor \& Francis.

Fornell, C., \& Larcker, D. F. (1981). Evaluating structural equation models with unobservable variables and measurement error. Journal of Marketing Research, 18(Feb), 39-50.

Galbraith, J. R. (1973). Designing complex organizations. MA: Addison-Wesley.

Garmaki, M., Boughzala, I., \& Wamba, S. F. (2016). The effect of Big Data Analytics Capability on Firm Performance. PACIS.

Gartner. (2013). Gartner Survey Reveals That 64 Percent of Organizations Have Invested or Plan to Invest in Big Data in 2013. 
George, G., Haas, M. R., \& Pentland, A. (2014). Big Data and Management. Academy of Management Journal, 57(2), 321-326.

Germann, F., Lilien, G. L., Fiedler, L., \& Kraus, M. (2014). Do retailers benefit from deploying customer analytics? Journal of Retailing, 90, 587-593.

Giannoccaro, I. (2018). Centralized vs. decentralized supply chains: The importance of decision maker's cognitive ability and resistance to change. Industrial Marketing Management, 73(December 2017), 59-69. Elsevier.

Gibb, F., Thornley, C., Ferguson, S., \& Weckert, J. (2011). The application of RFIDs in libraries: An assessment of technological, management and professional issues. International Journal of Information Management, 31, 244-251.

Grover, V., Chiang, R. H. L., Liang, T. P., \& Zhang, D. (2018). Creating Strategic Business Value from Big Data Analytics: A Research Framework. Journal of Management Information Systems, 35(2), 388-423.

Guide, V. D. R., \& Ketokivi, M. (2015). Notes from the Editors: Redefining some methodological criteria for the journal. Journal of Operations Management, 37, v-viii.

Gunasekaran, A., Papadopoulos, T., Dubey, R., Wamba, S. F., Childe, S. J., Hazen, B., \& Akter, S. (2017). Big data and predictive analytics for supply chain and organizational performance. Journal of Business Research, 70, 308-317. Elsevier Inc.

Gupta, M., \& George, J. F. (2016). Toward the development of a big data analytics capability. Information \& Management, 53, 1049-1064.

Gupta, S., Rudd, J., \& Lee, N. (2014). Business Sustainability through successful integration of Marketing and Operations. Industrial Marketing Management, 43(1), 3-5.

Gupta, S., Väätänen, J., \& Khaneja, S. (2016). Value added reseller or value at risk: The dark side of relationships with VARs. Industrial Marketing Management, 55, 110-118.

Hair, J. F., Anderson, R. E., Tatham, R. L., \& Black, W. C. (2005). Multivariate data analysis (7th ed.). Upper Saddle River, New Jersey: Prentice Hall.

Hair, J. F., Hult, G. T. M., Ringle, C., \& Sarstedt, M. (2013). A Primer on Partial Least Squares Structural Equation Modeling (PLS-SEM). United States: SAGE Publications.

Hair, J. F., Ringle, C. M., \& Sarstedt, M. (2011). PLS-SEM: indeed a silver bullet. Journal of Marketing Theory and Practice, 19, 139-152.

Hazen, B. T., Skipper, J. B., Ezell, J. D., \& Boone, C. A. (2016). Big data and predictive analytics for supply chain sustainability: A theory-driven research agenda. Computers and Industrial Engineering, 101, 592-598.

Henderson, J. C., \& Venkatraman, N. (1993). Strategic Align- ment: Leveraging Information 
Technology for Transforming Organizations. IBM Systems Journal, 32(1).

Henseler, J., Dijkstra, T. K., Sarstedt, M., Ringle, C. M., Diamantopoulos, A., Straub, D. W., \& Calantone, R. J. (2014). Common beliefs and reality about PLS: comments on Rönkkö and Evermann (2013). Organizational Research Methods, 17(2), 182-209.

Hitt, M.A., Xu, K., \& Carnes, C. M. (2016). Resource based theory in operations management research. Journal of Operations Management, 41, 77-94.

Hitt, Michael A., Bierman, L., Shimizu, K., \& Kochhar, R. (2001). Direct and Moderating Effects of Human Capital on Strategy and Performance in Professional Service Firms : A Resource-Based Perspective. Academy of Management Journal, 44(1), 13-28.

Kache, F., \& Seuring, S. (2017). Challenges and opportunities of digital information at the intersection of big data analytics and supply chain management. International Journal of Operations \& Production Management, 37(1), 10-36.

Keeso, A. (2015). Big data and environmental sustainability: a conversation starter. ( No. 14-04).

Kim, C., Oh, E., Shin, N., \& Chae, M. (2009). An empirical investigation of factors affecting ubiquitous computing use and U-business value. International Journal of Information Management, 29(6), 436-448.

King, A., \& Lenox, M. (2001). Lean and green? An empirical examination of the relationship between lean production and environmental performance. Production and Operations Management, 10(3), 244-256.

Kock, N. (2015). Common method bias in PLS-SEM: A full collinearity assessment approach. International Journal of e-Collaboration, 11(4), 1-10.

Kock, N., \& Lynn, G. S. (2012). Lateral collinearity and misleading results in variance-based SEM: An illustration and recommendations. Journal of the Association for Information Systems, 13(7), 546-580.

Kung, L., Kung, H. J., Jones-Farmer, A., \& Wang, Y. (2015). Managing big data for firm performance: a configurational approach. Americas conference on information systems (AMCIS).

Lotti, F., \& Santarelli, E. (2004). Industry Dynamics and the Distribution of Firm Sizes: A Nonparametric Approach. Southern Economic Journal, 70(3), 443.

Lu, Y., \& Ramamurthy, K. (2011). Understanding the link between information technology capability and organizational agility: An empirical examination. MIS Quarterly, 35, 931-954.

Mackey, A., Mackey, T. B., \& Barney, J. B. (2007). Corporate Social Responsibility and 
Firm Performance: Investor Prefereneces and Corporate Strategies. Academy of Management Review, Forthcoming, 32(3), 817-835.

Martin, J. A., \& Bachrach, D. G. (2018). A relational perspective of the microfoundations of dynamic managerial capabilities and transactive memory systems. Industrial Marketing Management, 74(August), 27-38.

Mata, F. J., Fuerst, W. L., \& Barney, J. B. (1995). Information technology and sustained com- petitive advantage: a resource-based analysis. MIS Quarterly, 19(4), 487-505.

Mikalef, P., \& Pateli, A. (2017). Information technology-enabled dynamic capabilities and their indirect effect on competitive performance: Findings from PLS-SEM and fsQCA. Journal of Business Research, 70, 1-16.

Mikalef, P., Pateli, A., \& Wetering, R. van de. (2016). IT flexibility and competitive performance: The mediating role of IT-enabled dynamic capabilities. Twenty-Fourth European Conference on Information Systems (ECIS). Istanbul: AIS Electronic Library (AISeL).

Nunnally, J. C., \& Bernstein, I. H. (1994). Psychometric Theory (3rd ed.). New York: McGraw-Hill.

Olszak, C. M. (2014). Towards an understanding business intelligence. A dynamic capability-based framework for Business Intelligence. Federated Conference on Computer Science and Information Systems (FedCSIS).

Papadopoulos, T., Gunasekaran, A., Dubey, R., Altay, N., Childe, S. J., \& Fosso-Wamba, S. (2017). The role of Big Data in explaining disaster resilience in supply chains for sustainability. Journal of Cleaner Production, 142, 1108-1118.

Pavlou, P. A., \& El Sawy, O. A. (2006). From IT leveraging competence to competitive advantage in turbulent environments: The case of new product development. Information Systems Research, 17(3), 198-227.

Pil, F. K., \& Rothenberg, S. (2003). Environmental performance as a driver of superior quality. Production and Operations Management, 12(3), 404-415.

Prescott, M. E. (2014). Big data and competitive advantage at Nielsen. Management Decision, 52(3), 573-601.

Priem, R. L., \& Butler, J. E. (2001). Is the Resourced-Base "View" a Useful Perspective for Strategic Management Research? Academy of Management Review, 26(1), 22-40.

Rajaguru, R., \& Matanda, M. J. (2013). Effects of inter-organizational compatibility on supply chain capabilities: Exploring the mediating role of inter-organizational information systems (IOIS) integration. Industrial Marketing Management, 42, 620- 
632. Elsevier Inc.

Roman Pais Seles, B. M., Lopes de Sousa Jabbour, A. B., Jabbour, C. J. C., de Camargo Fiorini, P., Mohd-Yusoff, Y., \& Tavares Thomé, A. M. (2018). Business opportunities and challenges as the two sides of the climate change: Corporate responses and potential implications for big data management towards a low carbon society. Journal of Cleaner Production, 189, 763-774.

Russom, P. (2011). Big data analytics. TDWI Best Practices Report, Fourth Quarter.

Schilke, O. (2014). On the contingent value of dynamic capabilities for competitive advantage: The nonlinear moderating effect of environmental dynamism. Strategic Management Journal, 35(2), 179-203.

Schoenherr, T. (2012). The role of environmental management in sustainable business development: A multi-country investigation. International Journal of Production Economics, 140(1), 116-128.

Schoenherr, T., \& Speier-Pero, C. (2015). Data science, predictive analytics, and big data in supply chain management: Current state and future potential. Journal of Business Logistics, 36(1), 120-132.

Singh, S. K., \& El-kassar, A. (2019). Journal of cleaner Production. Journal of Cleaner Production, 213, 1264-1273.

Sirmon, D. G., Hitt, M. A., Ireland, R. D., \& Gilbert, B. A. (2011). Resource Orchestration to Create Competitive Advantage: Breadth, Depth, and Life Cycle Effects. Journal of Management, 37(5), 1390-1412.

Smith, W. K., \& Tushman, M. L. (2005). Managing Strategic Contradictions: A Top Management Model for Managing Innovation Streams. Organization Science, 16(5), 522-536.

Srinivasan, R., \& Swink, M. (2018). An Investigation of Visibility and Flexibility as Complements to Supply Chain Analytics: An Organizational Information Processing Theory Perspective. Production and Operations Management, 27(10), 1849-1867.

Swaminathan, J. M. (2018). Big Data Analytics for Rapid, Impactful, Sustained, and Efficient (RISE) Humanitarian Operations. Production and Operations Management, 27(9), 1696-1700.

Székely, F., \& Knirsch, M. (2005). Responsible leadership and corporate social responsibility: Metrics for sustainable performance. European Management Journal, 23(6), 628-647.

Teece, D. J., Pisano, G., \& Shuen, A. (1997). Dynamic capabilities and strategic 
management. Strategic Management Journal, 18(7), 509-533.

Tellis, G. J., Yin, E., \& Bell, S. (2009). Global consumer innovativeness: Cross-country differences and demographic commonalities. Journal of International Marketing, 17(2), $1-22$.

Vidgen, R., Shaw, S., \& Grant, D. B. (2017). Management challenges in creating value from business analytics. European Journal of Operational Research, 261(2), 626-639. Elsevier B.V.

Waller, M. A., \& Fawcett, S. E. (2013). Click here for a data scientist: Big data, predictive analytics, and theory development in the era of a maker movement supply chain. Journal of Business Logistics, 34(4), 249-252.

Wamba, S. F., Gunasekaran, A., Akter, S., Ren, S. J., Dubey, R., \& Childe, S. J. (2017). Big data analytics and firm performance: Effects of dynamic capabilities. Journal of Business Research, 70, 356-365.

Wamba, S. F., Gunasekaran, A., Dubey, R., \& Ngai, E. W. T. (2018). Big data analytics in operations and supply chain management. Annals of Operations Research, 270, 1-4.

Wang, G., Gunasekaran, A., Ngai, E. W. T., \& Papadopoulos, T. (2016). Big data analytics in logistics and supply chain management: Certain investigations for research and applications. International Journal of Production Economics, 176, 98-110.

Wang, N., Liang, H., Zhong, W., Xue, Y., \& Xiao, J. (2012). Resource Structuring or Capability Building? An Empirical Study of the Business Value of Information Technology. Journal of Management Information Systems, 29(2), 325-367.

Winter, S. G. (2003). Understanding dynamic capabilities. Strategic Management Journal, 24(10 SPEC ISS.), 991-995.

Xu, P., \& Kim, J. (2014). Achieving Dynamic Capabilities with Business Intelligence. PACIS.

Zhao, R., Liu, Y., Zhang, N., \& Huang, T. (2017). An Optimization Model for Green Supply Chain Management by Using a Big Data Analytic Approach. Journal of Cleaner Production, 142, 1085-1097.

Zhou, Z.-H., Chawla, N. V., Jin, Y., \& Williams, G. J. (2014). Big Data Opportunities and Challenges: Discussions from Data Analytics Perspectives. IEEE Computational Intelligence Magazine, 9(4), 62-74.

Zhu, K., \& Kraemer, K. L. (2005). Post-adoption variations in usage and value of e-business by organizations: Cross-country evidence from the retail industry. Information Systems Research, 16(1), 61-84. 
Zhu, Q., \& Sarkis, J. (2004). Relationships between operational practices and performance among early adopters of green supply chain management practices in Chinese manufacturing enterprises. Journal of Operations Management, 22(3), 265-289.

Zhu, Q., Sarkis, J., \& Geng, Y. (2005). Green supply chain management in China: Pressures, practices and performance. International Journal of Operations and Production Management, 25(5), 449-468.

Zhu, Q., Sarkis, J., \& Lai, K. (2008). Confirmation of a measurement model for green supply chain management practices implementation. International Journal of Production Economics, 111(2), 261-273.

Zhu, Q., Sarkis, J., \& Lai, K. (2012). Examining the effects of green supply chain management practices and their mediations on performance improvements. International Journal of Production Research, 50(5), 1377-1394.

Zsidisin, G. A., \& Hendrick, T. E. (1998). Purchasing's involvement in environmental issues: A multi-country perspective. Industrial Management and Data Systems, 98(7), 313-320. 